\title{
Pituitary Adenomas: Possible Role of Bromocriptine in Intratumoral Hemorrhage ${ }^{1}$
}

\begin{abstract}
Magnetic resonance (MR) images of 68 patients examined for adenomas of the pituitary gland were retrospectively reviewed for the presence of hyperintensity on T1-weighted images because of recent reports suggesting that bromocriptine treatment may affect $T 1$ values. Twentyseven patients were examined after either surgery or radiation therapy, 29 were receiving bromocriptine, and 22 had not received any treatment at the time of MR imaging. MR imaging criteria showed evidence of subacute or chronic intratumoral hemorrhage in 18 patients, five of whom had hemorrhage proved at surgery. Ten of the 18 patients were asymptomatic from the hemorrhage; eight had headaches, visual field cuts, or cranial nerve deficits. Although an increased frequency of intratumoral hemorrhage was noted in prolactinomas and macroadenomas and in patients undergoing bromocriptine therapy, the effect of bromocriptine on bleeding was the only significant correlation $(P<.01)$.
\end{abstract}

Index terms: Bromocriptine - Pituitary, hemorrhage, $145.367 \bullet$ Pituitary, MR studies, 145.1214 - Pituitary, neoplasms, 145.37

Radiology 1989; 170:239-243
TNCREASED signal intensity on T1weighted images has been attributed to cholesterol or fat, melanin, subacute and chronic hemorrhage, and some proteins. During magnetic resonance (MR) imaging of 68 patients with treated or untreated adenomas of the pituitary gland, areas of hyperintensity within the tumor bed were frequently noted on T1-weighted images, particularly in patients receiving bromocriptine therapy. It has been proposed that this shortening of $\mathrm{T} 1$ values is due to a decrease in intracellular protein synthesis and water content or to a change in the molecular mobility of the adenoma cells that involute under bromocriptine therapy (1). The purpose of this communication is to evaluate the frequency of high T1 signal within pituitary adenomas, the relation of high T1 signal to bromocriptine treatment, and the cause of the increased T1 relaxation.

\section{PATIENTS AND METHODS}

Over a 15-month period, 68 patients with pituitary masses proved on clinical or pathologic examination to be adenomas were examined. All patients were imaged on a 1.5-T Signa (GE Medical Systems, Milwaukee) superconducting unit in T1-weighted coronal and sagittal planes with a repetition time (TR) of 500$700 \mathrm{msec}$, echo time (TE) of $20-30 \mathrm{msec}$ $(\mathrm{TR} / \mathrm{TE}=500-700 / 20-30) ; 3-5-\mathrm{mm} \mathrm{sec}-$ tion thickness with a $0-1.5-\mathrm{mm}$ gap, depending on tumor size; $256 \times 256$ matrix; four excitations; and $16-20-\mathrm{cm}$ fields of view. Supplemental proton-density and T2-weighted coronal images were also obtained (except in nonhemorrhagic microadenomas) with 2,000-3,000/50-100, 3-mm section thickness, 1-mm gap, $128 \times$ 256 matrix, one excitation, and $16-20-\mathrm{cm}$ fields of view. Axial images were obtained only if deemed necessary to optimize tumor localization. The images were reviewed by at least two neuroradiologists (D.M.Y., A.J.K.). The intensity characteristics of the pituitary adenomas were compared with the intensity of the normal pituitary gland, which, in the adult, approaches that of gray matter. The size of the tumor was measured at its maximum vertical or horizontal dimension on the coronal T1-weighted image.

The patients' hospital charts, office notes, pituitary hormonal levels, pathologic specimens, and surgical notes were reviewed to attempt to conclusively determine a cause of hyperintensity on $\mathrm{T} 1$ weighted images.

Of the 68 patients examined for pituitary adenomas, 17 were men and 51 were women, with an average age of 38 years (range, 10-85 years). Pituitary hormonal analysis revealed the following distribution of secreted hormones: prolactin, 39 (57\%) patients; adrenocorticotrophic hormone, two (3\%) patients; growth hormone, two (3\%) patients; multiple hormones, two (3\%) patients; and nonsecreting adenomas, $23(34 \%)$ patients (Table 1 ).

Seventeen patients were treated with surgery and/or radiation therapy alone. In ten patients, bromocriptine was added to the surgery or radiation therapy protocol. Nineteen patients were treated solely with bromocriptine, and 22 patients received no therapy before undergoing $M R$ imaging (Table 2).

Thirty-seven patients had macroadenomas defined as tumors with a maximum linear dimension of $1 \mathrm{~cm}$ or greater in the vertical or horizontal plane. Fifteen of the patients with macroadenomas were treated with bromocriptine, and 14 of the 31 patients with microadenomas received bromocriptine (Table 3 ).

The differences in intratumoral hemorrhage between the proportions of prolactinomas and nonsecreting adenomas, macroadenomas and microadenomas, and patients receiving and not receiving bromocriptine were tested with the twotailed critical ratio test for $P$ values.

\section{RESULTS}

Twenty-eight of the 68 patients with pituitary adenomas showed evidence of hyperintensity on T1weighted images (Table 4). In nine of these patients, who had undergone

Abbreviations: $\quad T E=$ echo time,$T R=$ repetition time. 
Table 1

Hormonal Analysis, Bromocriptine Therapy, and Intratumoral

Hemorrhage

\begin{tabular}{|c|c|}
\hline Hormone Secreted* & $\begin{array}{l}\text { No. of } \\
\text { Patients }\end{array}$ \\
\hline \multicolumn{2}{|l|}{ Prolactin $(n=39)$} \\
\hline Receiving $\mathrm{BC}$ & \\
\hline Receiving $\mathrm{BC}$ and bled & $13(50)$ \\
\hline Not receiving $B C$ & \\
\hline Not receiving $B C$ and bled & $0(0)$ \\
\hline Total bled & $13(33)$ \\
\hline $\mathrm{ACTH}(n=2)$ & \\
\hline Total bled & $0(0)$ \\
\hline Growth hormone $(n=2)$ & \\
\hline Total bled & $0(0)$ \\
\hline Multiple hormones $(n=2)^{\dagger}$ & \\
\hline \multirow{2}{*}{\multicolumn{2}{|c|}{$\begin{array}{l}\text { Nonsecreting adenomas } \\
\qquad(n=23)^{f}\end{array}$}} \\
\hline & \\
\hline Total & $\overline{68}$ \\
\hline
\end{tabular}

Note $-\mathrm{BC}=$ bromocriptine, $\mathrm{ACTH}=$ adrenocorticotrophic hormone.

- Numbers in parentheses are percentages.

† Both patients received bromocriptine.

¥ One patient received bromocriptine for nonsecreting adenoma that did not bleed.

surgery, fat packed within the sella during transsphenoidal hypophysectomy accounted for the short T1 value on the MR images. This was confirmed by the decrease in signal intensity on the second echo of the proton-density/T2-weighted sequence (Fig 1). Of the remaining 19 patients in whom bright $\mathrm{T} 1$ foci appeared, six underwent subsequent surgery. In five patients, subacute or chronic hemorrhage was discovered, and in one patient a fatty substance exuded from the adenoma (Figs 2-4). In the images of 13 patients who did not undergo surgery, hyperintense areas were thought to be caused by intratumoral hemorrhage, since the hemorrhages were hyperintense on T2-weighted images with the intensity greater than that of neighboring fat. This same pattern was seen in the five patients with intratumoral hemorrhage confirmed at surgery. In the one patient with the oily tumoral excretion, the T2-weighted intensity decreased and paralleled that of fat.

Of the five patients with intratumoral hemorrhage confirmed at pathologic examination and the 13 patients with suspected hemorrhage, $13(72 \%)$ had prolactin-secreting adenomas and five (28\%) had nonfunctioning adenomas (Table 1). Overall, $57 \%$ of pituitary adenomas were prolactin-secreting and $34 \%$ were nonfunctioning, so an increased frequency of bleeding was seen in prolactinomas. One-third of prolactinomas bled, whereas $22 \%$ of nonsecreting adenomas bled. This difference was not significant $(P=.516)$.

Table 2

Treatment Modalities in Patients with Pituitary Adenomas at Time of MR Imaging

\begin{tabular}{|c|c|c|c|c|}
\hline \multirow[b]{2}{*}{ Treatment } & \multirow[b]{2}{*}{$\begin{array}{l}\text { No. of } \\
\text { Patients }\end{array}$} & \multirow{2}{*}{$\begin{array}{c}\text { Bright Area } \\
\text { on T1 } \\
\text { Images }\end{array}$} & \multicolumn{2}{|c|}{$\begin{array}{c}\text { Cause of } \\
\text { Shortened T1 }\end{array}$} \\
\hline & & & $\begin{array}{l}\text { Postoperative } \\
\text { Fat Packing }\end{array}$ & Bleeding \\
\hline \multicolumn{5}{|l|}{ Surgery } \\
\hline Alone & 6 & 4 & 4 & $0(0)$ \\
\hline With radiation therapy & 10 & $6^{*}$ & 4 & $1(10)$ \\
\hline With BC & 0 & 0 & 0 & $0(0)$ \\
\hline With radiation therapy and $B C$ & 10 & 1 & 1 & $0(0)$ \\
\hline \multicolumn{5}{|l|}{ Radiation therapy } \\
\hline Alone & 1 & 0 & 0 & $0(0)$ \\
\hline With BC & 0 & 0 & 0 & $0(0)$ \\
\hline BC only & 19 & 13 & 0 & $13(68)$ \\
\hline No treatment & 22 & 4 & 0 & $4(18)$ \\
\hline Total receiving $\mathrm{BC}$ & 29 & 14 & 1 & $13(45)$ \\
\hline Total not receiving $B C$ & 39 & 14 & 8 & $5(13)$ \\
\hline Total & 68 & $28^{*}$ & 9 & $18(26)$ \\
\hline
\end{tabular}

Note. - Numbers in parentheses are percentages.

* One patient had ACTH-secreting macroadenoma containing cholesterol.

Table 3

Size of Lesion and Relationship to Intratumoral Hemorrhage

\begin{tabular}{ccccc}
\hline Patient Category & $\begin{array}{c}\text { Macroadenomas } \\
(n=37)\end{array}$ & $\begin{array}{c}\text { Average } \\
\text { Size }(\mathrm{cm})\end{array}$ & $\begin{array}{c}\text { Microadenomas } \\
(n=31)\end{array}$ & $\begin{array}{c}\text { Average } \\
\text { Size }(\mathrm{cm})\end{array}$ \\
\hline Receiving BC & 15 & 2.1 & 14 & 0.57 \\
Receiving BC and bled & $7(47 \%)$ & 2.3 & $6(43 \%)$ & 0.67 \\
Not receiving BC & 22 & 2.0 & 17 & 0.58 \\
Not receiving BC and bled & $4(18 \%)$ & 2.0 & $1(6 \%)$ & 0.60 \\
\hline
\end{tabular}

Note.-Eleven of $37(30 \%)$ macroadenomas bled and averaged $2.2 \mathrm{~cm}$ in size. Seven of $31(23 \%)$ microadenomas bled and averaged $0.66 \mathrm{~cm}$ in size $(P=.697)$.

Table 4

Causes of $\mathrm{T} 1$ Hyperintensity in 28 Patients

\begin{tabular}{cc}
\hline No. of \\
Cause & Patients \\
\hline
\end{tabular}

Postoperative fat packing

Fat containing adenoma

Subacute or chronic intratumoral hemorrhage

Confirmed at surgery

Presumed on the basis of $\mathrm{T} 1$ and T2 signal characteristics Total

9
9
1 5

13

$\frac{13}{28}$$$
\text { Total }
$$

All 13 patients with prolactinomas that had intratumoral hemorrhage were receiving bromocriptine. Thus, 13 of $29(45 \%)$ patients that received bromocriptine had intratumoral hemorrhage, compared with five of 39 (13\%) who did not receive bromocriptine (Table 2). This difference was statistically significant $(P<.01)$. Thirteen patients with prolactinomas had not received bromocriptine, and none of these prolactinomas showed intratumoral hemorrhage (Table 1).

The duration of bromocriptine treatment before hemorrhage was detected ranged from 1 month to 4
Table 5

Symptoms of Patients with Intratumoral Hemorrhage

\begin{tabular}{cc}
\hline Symptom & No. of \\
Patients
\end{tabular}

No symptoms
Headache
New visual field cut
New cranial nerve deficit
Hypopituitarism
10 New cranial nerve deficit Hypopituitarism

* Three of these five patients also had headaches.

years; six patients with hemorrhage were detected before 12 months of treatment and seven were detected after that time. Since the imaging intervals were not standardized (but imaging was performed annually in most asymptomatic patients), the hemorrhage could have occurred at any point within these intervals. Additionally, in nearly all patients, the preceding study was computed tomography (CT), which may not have been sensitive to hemorrhage.

Eleven of the $18(61 \%)$ patients with intratumoral bleeding had macroadenomas, a figure that compares 


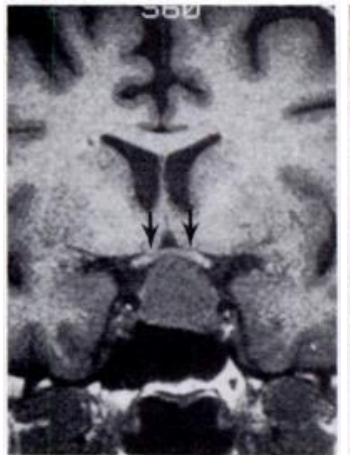

a.

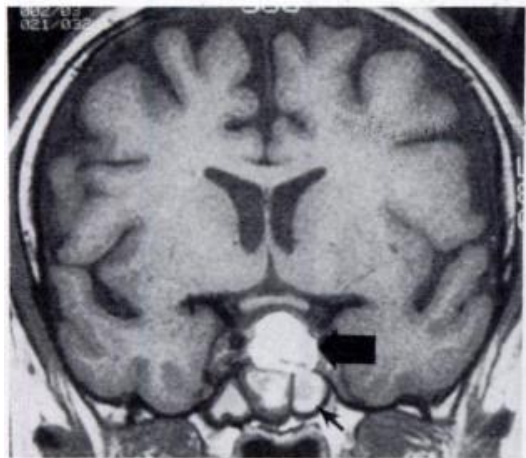

b.

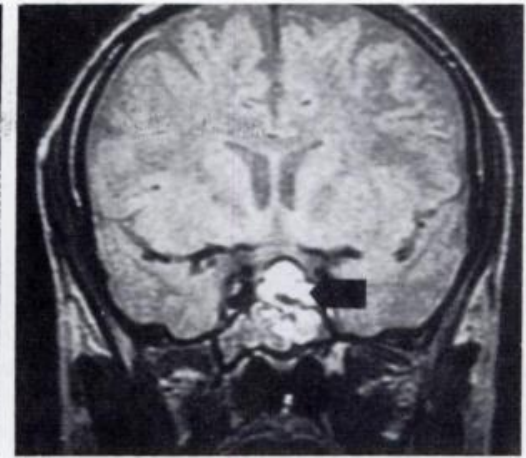

c.

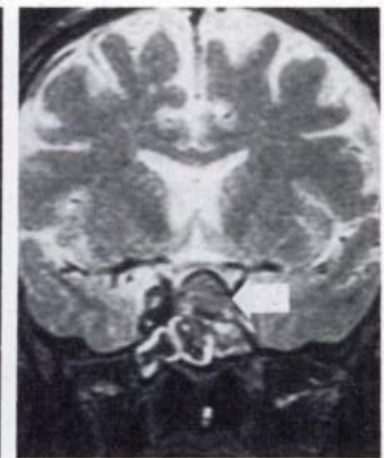

d.

Figure 1. (a) Preoperative T1-weighted coronal image of a 44-year-old woman with a hypointense prolactinoma demonstrates bowing of the optic chasm (arrows) by the sellar mass. (b-d) Images after transsphenoidal hypophysectomy demonstrate typical MR features of sellar fat packing. Fat (large arrow) in $b$ is hyperintense on the coronal T1-weighted sequence. Fat within the sphenoid sinus is also present (small arrow) in b. Fat (arrow) in c is hyperintense on the proton-density image but shows signal loss (arrow) in d on the second-echo T2-weighted sequence.

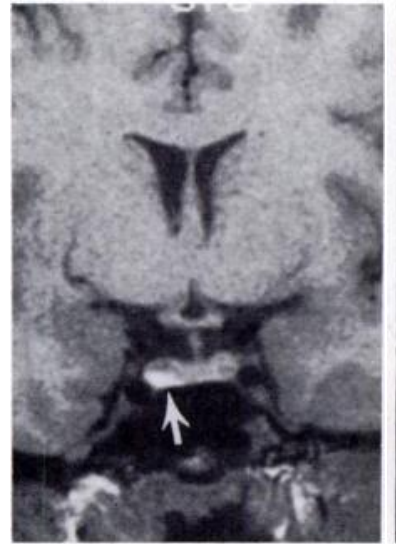

a.

Figure 2. Images of hemorrhagic prolactin-secreting microadenoma in a 37-year-old woman with amenorrhea and galactorrhea who underwent bromocriptine therapy for 2 years.

The 7-mm lesion is hyperintense just to the right of midline (arrow) on all three coronal sequences: (a) T1-weighted, (b) proton-density, and (c) T2-weighted. The persistent hyperintensity on T2-weighted images suggests subacute or chronic intratumoral hemorrhage.
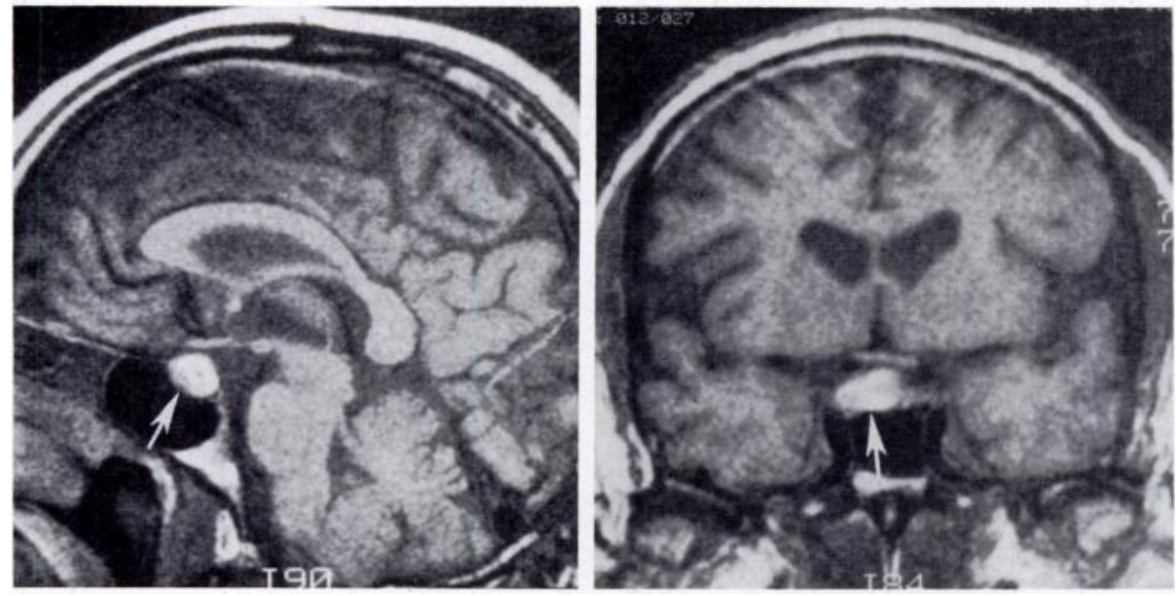

b.

Figure 3. Images of intratumoral hemorrhage in a chromophobe macroadenoma in a 55year-old man with visual field deficits and palsy of the right third cranial nerve. The tumor is hyperintense (arrow) on sagittal (a) and coronal (b) T1-weighted images.

with $54 \%$ overall. Thirty percent of macroadenomas bled, versus $23 \%$ of microadenomas (Table 3). The difference between the frequency of bleed- ing in macroadenomas and that in microadenomas was not statistically significant $(P=.697)$. The average size of the macroadenomas that bled
$(2.2 \mathrm{~cm})$ was nearly identical to that of nonhemorrhagic macroadenomas $(2.1 \mathrm{~cm})$. Similarly, the size of $\mathrm{mi}$ croadenomas that bled $(0.66 \mathrm{~cm})$ was less than $0.1 \mathrm{~cm}$ greater than the size of those that did not bleed $(0.57 \mathrm{~cm})$. The average size of bromocriptinetreated, bleeding macroadenomas $(2.3 \mathrm{~cm})$ and microadenomas $(0.67$ $\mathrm{cm})$ was comparable to the bleeding tumors that were not treated with bromocriptine $(2.0$ and $0.6 \mathrm{~cm}$, respectively) (Table 3 ).

In most patients with intratumoral hemorrhage (Table 5), the finding at MR imaging of blood within the tumor was serendipitous (ten of 18 patients). Six patients had recent onset or exacerbation of headaches, three had new visual field deficits, and two had extraocular neuromuscular changes. Three of these patients had more than one symptom. No patients had acute change in hormonal function as their presenting symptom or a catastrophic presentation.

\section{DISCUSSION}

In our institution, fat and fascia are routinely packed in the sella during transsphenoidal hypophysectomy. The fat packed in the sella displays imaging characteristics comparable to those of neighboring bone marrow fat and appears hyperintense on T1 weighted and proton-density images, with the intensity decreasing on second-echo T2-weighted images. Chemical shift artifacts from the fat may also suggest its presence (2). Thus, after surgery in nine patients, the bright areas on T1-weighted images were confirmed to be fat packing.

Several reports have described the histopathologic characteristics of pituitary adenomas after treatment with bromocriptine, an ergot deriva- 


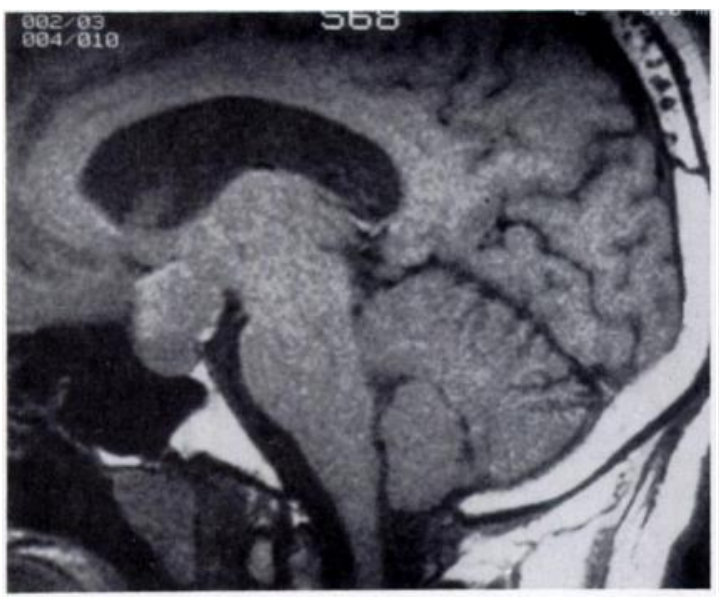

a.

Figure 4. Sagittal T1-weighted (a), coronal T1-weighted (b), and coronal T2-weighted (c) images demonstrate a hyperintense 3-cm sellar mass in a 22-year-old man with hyperprolactinemia, long-standing peripheral visual field cut, and worsening severe headache. He had begun treatment with bromocriptine 2 months previously, and a CT scan at that time showed no hemorrhage within this macroadenoma. A chronic clot within a macroprolactinoma was found at surgery.

tive that functions as a dopaminergic agonist that decreases prolactin secretion by the pituitary gland (3-6). After short-term treatment with bromocriptine, histologic examination reveals a decrease in cell volume, particularly within the cytoplasmic compartment of the cell. There is a concomitant decrease in cellular ribosomes, rough endoplasmic reticulum, and Golgi complexes, which corresponds to a decline in protein synthesis. No definite cell necrosis, vascular thrombosis, pituitary infarction, or hemorrhage has been reported from short-term bromocriptine therapy, although one report does raise the possibility of central tumor necrosis after long-term bromocriptine treatment (3-6). Maximum shrinkage of tumor volume appears to occur within 3 weeks of institution of the drug.

On the basis of these histopathologic observations, Weissbuch proposed an explanation for the MR imaging signal changes in pituitary adenomas after bromocriptine therapy (1). He stated that a reduction in $\mathrm{T} 1$ values may be due to a decrease in cellular and tissue water seen in involuting cells or to a change in molecular mobility that causes the frequency of water-proton collisions to occur closer to the Larmor frequency (1). Bromocriptine treatment can change molecular mobility by altering intracellular contents because of the decreased protein synthesis and fewer protein-synthesizing organelles. Weissbuch further postulated that necrotic or edematous cells, increased extracellular water, and leaked proteins from dying cells could alter the T1-weighted MR im- aging signal characteristics in the involuting prolactin-secreting adenoma (1). Weissbuch's explanation offers several obtuse factors that may contribute to MR imaging signal changes but does not satisfactorily clarify why all adenomas treated with bromocriptine do not exhibit this T1 hyperintensity.

Hemorrhage is clearly one of the pathologic occurrences that creates a complex interplay of $\mathrm{T} 1$ and $\mathrm{T} 2$ relaxation times. Intratumoral hemorrhage is common in pituitary adenomas and was suggested in five patients with nonfunctioning tumors in this series. In 13 patients treated with bromocriptine, surgical proof or MR imaging signal characteristics suggested intratumoral hemorrhage. The surgical proof in all patients was obtained with visual inspection of the tumor. In many patients, the pituitary adenoma is soft and friable after bromocriptine therapy, and microscopic evidence of hemorrhage after histologic fixing may be attributed to bleeding at surgery. Nonetheless, pathologic correlation with intraoperative assessment by the surgeon for intratumoral hemorrhage was obtained. No area of fat, melanin, or protein deposition was seen on pathologic examination; one oily tumor exudate was high in cholesterol concentration.

The competing effects of intracellular and extracellular methemoglobin, deoxyhemoglobin, hemosiderin, and magnetic field heterogeneities causing local magnetic gradients may lead to hypointense or isointense $T 1$ signal acutely. However, the overwhelming effect of free extracellular methemoglobin causes $\mathrm{T} 1$ shortening in the subacute and chronic course. T2 hyperintensity tends to trail the $\mathrm{T} 1$ shortening and is of less value in detecting hemorrhage but helps in differentiating it from fat. Decreased signal due to the paramagnetic field effects of hemosiderin is frequently seen in intracerebral hemorrhage but much less frequently in intratumoral hemorrhage in pituitary adenomas, since these extracerebral tumors lack a blood-brain barrier, and the accumulation of hemosiderin-laden macrophages does not usually occur (7-9).

In several other reports of findings at MR imaging in pituitary adenomas, anecdotal cases of postbromocriptine intratumoral bleeding have been described (10-13). To our knowledge, ours is the first large series to emphasize this occurrence in bromocriptine-treated prolactinomas The frequency of intratumoral hemorrhage in all pituitary adenomas has been gathering increased attention, as MR imaging has made hemorrhagic foci easier to detect. Overall, 18 of $68(26 \%)$ pituitary adenomas showed evidence of hemorrhage on MR images. Thirteen of $29(45 \%)$ patients treated with bromocriptine showed intratumoral hemorrhage, while only five of $39(13 \%)$ patients not treated with bromocriptine had evidence of hemorrhage $(P<.01)$. These numbers compare with a surgical report of intratumoral hemorrhage in $16.1 \%$ of 560 cases of pituitary adenoma (14). In the study by Wakai et al, no significant correlation with size, hormonal secretion, or sex was found. They also raised the possibility of the influence of bromocriptine in the development of intratumoral hemorrhage (14). 
The time course of hemorrhage after institution of bromocriptine therapy was variable; the patients in our study were nearly evenly split into those treated less than and more than 1 year. Of interest were the clinical findings that $55 \%$ of the patients were asymptomatic. Wakai et al found that $43 \%$ of 93 patients with intratumoral hemorrhage were asymptomatic (14). Only $39 \%$ of their patients had a major episode associated with bleeding, and, as in our study, the symptoms were due to mass effect (eg, headache, visual changes, or new cranial nerve abnormalities [14]). No symptoms due to hormonal abnormalities or panhypopituitarism were found. The "catastrophe" of pituitary apoplexy was not the presenting complaint in any of the patients in our study. This leads one to wonder if the headache associated as a common side effect of bromocriptine therapy may be attributable to microscopic bleeding into the tumor. Could the headache be a sign that these patients are at risk for subsequent macroscopic intratumoral hemorrhage?

Because the results of this preliminary paper suggest that bromocriptine may induce intratumoral hemorrhage, we believe a prospective study should be undertaken in patients with pituitary adenomas who are receiving this drug. The intensity changes before and after institution of bromocriptine, the frequency of bromocriptine-induced headaches with and without evidence of intratumoral hemorrhage, and the frequency of headaches with and without bromocriptine therapy should be examined. The high frequency of intratumoral hemorrhage in pituitary adenomas treated and not treated with bromocriptine should be corroborated.

Acknowledgments: Many thanks go to Betty Brandt and Valerie Tsafos for the preparation of the manuscript and to Harold Kundell, MD for assistance with statistical analysis.

\section{References}

1. Weissbuch SS. Explanation and implications of MR signal changes within pituitary adenomas after bromocriptine therapy. AJNR 1986; 7:214-216.

2. Nishimura K, Fujisawa I, Togashi K, et al. Posterior lobe of the pituitary: identification by lack of chemical shift artifact in MR imaging. J Comput Assist Tomogr $1986 ; 10: 899-902$.

3. Anniko M, Wersall J. Morphological changes in bromocriptine-treated pituitary tumours. Acta Otolaryngol 1983. 96:337-353.

4. Barrow DL, Tindall GT, Kovacs K, Thorner MO, Horvath E, Hoffman JC Jr. Clinical and pathological effects of bromocriptine on prolactin-secreting and other pituitary tumors. J Neurosurg 1984; 60:1-7.

5. Gen $M$, Uozumi T, Ohta M, Ito A, Kajiwara H, Mori S. Necrotic changes in prolactinomas after long term administration of bromocriptine. J Clin Endocrinol Metab $1984 ; 59: 463-470$.
6. Rengachary SS, Tomita $T$, Jefferies $B F$, Watanabe I. Structural changes in human pituitary tumor after bromocriptine therapy. Neurosurgery 1982; 10:242-251.

7. Gomori JM, Grossman RI, Goldberg HI, Zimmerman RA, Bilaniuk LT. Intracranial hematomas: imaging by high-field MR. Radiology 1985; 157:87-93.

8. Zimmerman RD, Deck MDF. Intracranial hematomas: imaging by high-field MR (letter). Radiology 1986; 159:565.

9. Zimmerman RD, Heier LA, Snow RB, Liu DPC, Kelly AB, Deck MDF. Acute intracranial hemorrhage: intensity changes on sequential MR scans at $0.5 \mathrm{~T}$. AJR 1988; 150:651-661.

10. Karnaze MG, Sartor K, Winthrop JD, Gado MH, Hodges FJ III. Suprasellar lesions: evaluation with MR imaging. Radiology 1986; 161:77-82.

11. Kucharczyk W, Davis DO, Kelly WM, Sze G, Norman D, Newton TH. Pituitary adenomas: high-resolution MR imaging at 1.5 T. Radiology 1986; 161:761-765.

12. Kulkarni MV, Lee KF, McArdle CB, Yeakley JW, Haar FL. 1.5-T MR imaging of pituitary microadenomas: technical considerations and CT correlation. AJNR 1988; 9:5-11.

13. Pojunas KW, Daniels DL, Williams AL Haughton VM. MR imaging of prolactinsecreting microadenomas. AJNR 1986; 7:209-213.

14. Wakai S, Fukushima $T$, Teramoto A, Sano K. Pituitary apoplexy: its incidence and clinical significance. J Neurosurg 1981; 55:187-193. 